$$
\text { -Journal Publications • Research Consultancy }
$$

\title{
THE CONCEPT OF ACTION RESEARCHES AMONG SECONDARY SCHOOL FEMALE TEACHERS IN MAKKAH AND ITS ROLE IN IMPROVING THEIR PROFESSIONAL PRACTICES AND INNOVATION
}

\author{
DR. HANIYEH ABDULLAH SIRAJ SAADAWI \\ Associate Professor - College of Education - Umm Al-Qura University - Kingdom of Saudi Arabia
}

\begin{abstract}
The aim of the research is to identify the reality of the concept of action research among secondary-school female teachers in Makkah, discerning their role in improving their professional and creative practices, and to detect whether or not there are statistically significant differences which reflect the responses of the teachers to their knowledge of the role of action research in improving their professional practices and creativity, which can be attributed to the differences in qualification, specialization, years of experience, teaching and taking training courses in action researches, through using a questionnaire consisting of eight axes, applied to a random sample of (135) female teachers from secondary schools in the Holy Makkah. The researcher relied on the descriptive, analytical and mixed approach (quantitative - qualitative).The research found the availability of medium practices related to the dimensions of action researches for secondary school teachers in Makkah. The results also revealed that there were no statistically significant differences among the averages of secondary-school teachers' responses concerning their knowledge of the role of action researches. The research recommended focusing on practicing the application of action researches in schools.
\end{abstract}

KEY WORDS: Action Research - Science Teachers - High (Secondary) School - Professional Practices \& Improvement

Received: Jun 13, 2020; Accepted: Jul 04, 2020; Published: Aug 12, 2020; Paper Id.: IJESRAUG20208

\section{INTRODUCTION}

Action research has emerged, as Al-Khaldi (2003: 12) pointed out, as an introduction to improving the practices of professional and academic teachers, andHewitt \&Little (2005: 1) added that action research helps the teacher to develop himself professionally, to integrate his knowledge of specialization and the methods and strategies of his teaching, to increase his analytical capabilities, his own awareness and critical thinking, and it contributes to improving communication among teachers, educational researchers, school administration and the outside community. Among the very rare Arab projects, is the initiative of the Middle East Institute for Higher Education in Education at the American University in Cairo, which aims at achieving high quality in schools through the application of the methodology of action research, in cooperation with the colleges of education, the Ministry of Education, and other institutions, to create a new educational shift based on the school's needs and its ability to face its problems, on its own, through a collaborative work that aims at finding practical and thoughtful solutions for the problems that the school faces, developing professional practices for teachers and ensuringtheir growth. Newman and King (2000) also stressed the importance of cooperative culture in teachers' action researchesbecause new information and ideas do not arise from individual learning, with traditional methods of professional development, but rather through dialogue and interaction with others and the creation of a culture of continuous learning. 
As many studies, such as (Mertler, 2006, Mertler, Garcia 2008, and Robin GarciaRobinStringer, 2007 and Chiouhui, 2011) have stressed the importance of encouraging teachers to embrace action research because it increases his motivation and gives him the opportunity to search, investigate, evaluate and practice critical thinking skills. Consequently, and after proving the importance of action research in improving the teachers' educational practices, professional development and innovation, this research is consistent with the recent trendsfor detecting the reality of the concept of action research for high-school teachers in the Holy Makkah, and its role in improving their professional practices and innovation.

\section{THE PROBLEM OF THE STUDY}

The Ministry of Education has put forward a number of development projects which aim at improving the educational process, including: the Comprehensive Curriculum Development Project, the Science and Mathematics Curriculum Development Project, the Curriculum System Project, the Teaching Strategies Development Project. Teachers are effective component of the success of these educational projects when they are better developed according to the goals of these development projects and the aspirations of those who are in charge of them.

Besides, the educational supervision, which aims at improving the educational, vocational practices and the innovation of male and female teachers through multiple luminous methods, suffers from a failure to achieve its goals. Many studies, including: The Khedidi Study (1434), Al-Rumaih (1425) and Al-Zahrani (1425) indicate poor practices of the educational supervision, as it does not provide real opportunities for the professional growth of male and female teachers, and rarely contributes to solving professional problems.

Moreover, the reality of in-service training programs targeting male and female teachers for the success of these projects and the advancement of the educational and educational process almost touches the inability of the male and female teachers to put the content of these programs into practice and application in the school where they work, where a limited number of teachers are chosen to attend these programs. This isreflected negatively on the practice of male and female teachers, and consequently,on the level of the academic achievement of male and female students. Al-Ansari's study (2004) indicated the low training opportunities available for teachers, its reliance on simple presentation and discussion, and its lack of practical practice. Shahrani's (2011) and Al-Harbi's (2011) studiesalso showed a decrease in the level of the graduates of the colleges of education, and the level of the performance of general education teachers. They also referredto the gap between what training programs offer during the service and what the teacher actual traditional practices in the classroom, which depend on the method of indoctrination where the theoretical side prevails over the practical one and, hence, its inability to effect a positive change in female teachers' practices in a way that reflects improvement in the learning of male and female students.Through her experience in supervising female teacher students while performing in schools, Sa'adawi (2016) agrees with them.

Likewise, at the school level, Rawas (2001) pointed out that the professional development as per teachers may encounter many problems, as some school principals oppose the exit of teachers to join in-service training programs during official working hours because there are no extra teachers to replace them.Besides, some teachers refrain from evening training programs because of the poor incentives. This can be applied to school principals and their teachers as well. In this regard, Al-Antar (1434) and Al-Tamimi (1430) see the need of school principals and managers for training programs that 
enable them to play their part in encouraging male and female teachers to improve their practices and promote their professional and innovative development.The Al-Zaidi Study (2013) also emphasized the need to establish a culture of professional development and innovation in secondary schools, and encourage individual and collective professional practices.

From the above, we conclude that there is a the necessity for a qualitative shift in the methods of professional development of female teachers towards modern and innovative methods that start from the school and invest their experiences in providing opportunities for their own learning, which is reflected in improving their practices by adopting action researches and employing them in developing a culture of teamwork, cooperation and exchange of experiences. Because of the above mentioned, the idea of the current research comes to the researcher's mind through identifying the reality of the concept of action research among high school teachers in the Holy Makkah in order to improve their professional practices and innovation. The current research seeks to answer the following questions:

- What is the concept of action research among high school teachers in Makkah from the teachers' point of view?

- What is the role of action research in improving professional practices and innovation among high school teachers in Makkah from their own point of view?

- Are there any statistically significant differences among the averages of responses of secondary school teachers in the Holy Makkah about their knowledge of the role of action research in improving professional practices and innovation attributable to the difference in qualification, specialization and experience in teaching and obtaining training courses in action research?

\section{SIGNIFICANCE OF THE STUDY}

This research derives its importance from being in harmony with modern trends in the professional development of female teachers by transforming schools into professional learning societies to improve and enable teachers to perform their educational, vocational and professional practices and innovation, making them active and critical and reflective practitioners, and also to enhance their professional growth, and to promote the concept of lifelong self-learning in them.

It is hoped that the results of the current research will contribute to the dissemination and development of the concept of action research among teachers through knowledge of its reality.

Finally, drawing the attention of officials to the importance of including action research in teacher preparation and training programs.

\section{OBJECTIVES OF THE STUDY}

The current research aims to identify the reality of the concept of verb research among high school teachers in Makkah.

Knowing the role of action research in improving professional practices and innovation among female teachers in secondary schools in Makkah from their point of view.

Disclose the statistically significant differences between the responses of secondary school teachers in the Holy Makkah about their knowledge of the role of action research to improve professional practices and innovation, which are attributed to the difference of variables (qualification, specialization and experience in teaching and access to training courses in action research. 


\section{THE LIMITS OF THE STUDY ARE AS FOLLOW}

The search was confined to the following limits:

- SUBJECT LIMITS:The research was limited to dealing with the subject of action research among the teachers because it is in harmony with the main research variable in order to improve their professional practices and innovation, and the resulting attainment of professional development.

- HUMAN LIMITS:The research was limited to surveying the opinion of female teachers in government secondary schools for girls in the Holy Makkah about the concept of action research.

- $\quad$-SPATIAL LIMITS:The field study was applied to some secondary schools for girls in Makkah.

- $\quad$ TIME LIMITS:The research was applied at the end of the second semester 1439 AH-2018.

\section{PROCEDURAL TERMINOLOGY OF ACTION RESEARCH}

- ACTION RESEARCH: It is an organized research conducted by female teachers, researchers, administrators and all those concerned with teaching matters and the learning environment, aiming at collecting information and data to overcome school problems in a scientific way, and to improve their professional, educational practices in the school. This makes them able to understand their work better,which is positively reflected on their professional development.

- $\quad$-PROFESSIONAL PRACTICES: The teacher uses knowledge and skills related to the teaching and learning processes efficiently and effectively in the light of her sense of responsibility, self-accountability, reinforced with effective communication and excellence in the performance of her ideas and practices in school. This requires her knowledge of the developments in her field of specialization and educational technology, keeping up with the latest to master it.

- THE CONCEPT OF INNOVATION: It is a mental process that reflects radical, quantitativechanges in structural organizations, the processes, and the production,which leads to increasing national and institutional riches, and to new, unconventional methods of performance that are used in carrying out and developing things and ideas.

\section{THEORETICAL FRAMEWORK AND PREVIOUS STUDIES}

Professional and innovative development has become one of the urgent issues at the forefront of educational reform in the world since pre-service teacher preparation programs are no longer sufficient to meet the emerging changes, and the role of the teacher has become limited to indoctrination and knowledge transfer.To achieve the concept of a teacher's professional development, and a qualitative change in the nature of her professional practices, we should create a school culture that enhances the values of joint cooperative work among its employees, because the school is seen as a pivotal center for providing continuous learning opportunities for teachers and improving their professional practices, which is reflected positively on the students at the secondary level by preparing them to be eligible to continue higher education and enter into the real world of work though making them the focus of the educational process so that they can develop higher thinking skills and self-learning through the qualitative education they receives. Therefore, a need arises for improving the quality of professional development programs and the opportunities for continuous learning that achieves the professional 
growth of the teachers and constantly renews it. To meet the emerging educational needs, action research is one of the latest methods that develop teachers, individuals and groups in the school community.

\section{THE CONCEPT OF ACTION RESEARCH}

Action research, as defined by Kemmis et al. (2002: 8) and McCainef (2008: 12), consists of two words, the word 'action' means intervention and procedure, and the word 'search' means induction and meditation, which is known as procedural research through which new knowledge is built, as defined by Zikra (2003: 29) as experimenting with ideas in practice to develop and increase knowledge. Naiff (2014: 2) defined action research as "a term referring to the scientific method of looking at work to make sure it is going as it should be.Because action research is carried out by the teacher (the practitioner), it is a teacher-based research, and because it requires the teacher to think and meditate on his work in the classroom and at school, so it is a practice based on self-reflection". Whereas, Good( 2008: 6) defines action research as "the process that practitioners undertake in an attempt to study their problems in a scientific way in order to be guided, corrected, or evaluated in their performance and decisions." Darling (2006) and Norton (2009) added that action research is a systematic approach to research undertaken by the members of the educational process, including teachers, administrators and supervisors,aiming at developing solutions to the problems they face in the educational process insidea school community.

Through the above discussion of the various meanings of action research, it is possible to come up with the following set of basic elements that action research practitioners perform in the educational field:

- Reviewing the current educational practices.

- Identifying and tracking the problem or issue by reflecting on the current practices

- Female teachers are self-motivated to conduct this type of research according to a specific methodology based on observation and data collection to seek solutions for the professional problems facing them, then experiment and evaluate these solutionsso as to improve their professional practices and, consequently, their teaching performance.

It is noted that action research is a tool or means used by all the members of the school community to overcome their problems and guide their practices and professional development through the use of scientific research steps to solve problems, which leads to improving the educational process. This requires possessing the necessary competencies to do it. It can be said that action research is based on learning through practice, cooperation, reflection, and interaction among teachers so as to improve their professional practices.

\section{SCHOOL CULTURE AND ITS RELATION TO ACTION RESEARCH}

The culture of action research is a reflection of the school culturewhich reflects the values that the members of the school community believe in, and expresses their professional behaviors and practices. Peterson (2002) believes that a school culture affects the way school personnel think, feel, and interact with this school. This point of view asserts thata school culture plays an active role in shaping the nature of the professional practices existing among the members the school. Sergiovanni (2006) emphasizes that commitment and high performance are a hallmark of schools with a positive organizational culture. 
Deal and Peterson (2009: p.10) summarize the impact of school culture on the attitudes, expectations, and beliefs of teachers about their professional practices as follows:

- The way teachers work collaboratively or individually

- The degree of trust between administrators and teachers

- The importance of professional development for teachers

- The primary responsibility of teachers is to teach students

- Common language and topics that teachers talk about

- $\quad$ The support and encouragement they provide to creative and innovative teachers

- Their belief in the impact of the social backgrounds from which students come from on determining their learning abilities.

They also listed a set of common, organizational values that can be derived as follows:

- Confidence

- the support

- Appreciation and recognition

- Fellowship

- Cooperation

- Experimentation

- Open communication using technology

- $\quad$ Participating in decision-making

It can be concluded that action research is an extension of the school's culture, directing their behaviors towards professional and innovative practices, as it is considered an effective tool in achieving professional and innovative development for the teachers.

\section{JUSTIFICATION FOR USING ACTION RESEARCH}

There are many justifications that lead to the use of action research in the educational field, as set out by Ahmed (2011: 60), Odeh (2004: 930), and Mckinef (2001: 8). Some of them are:

- It is a method for solving educational problems.

- It is not used individually but in groups.

- A methodology characterized by awareness of performance, development of critical thinking and cooperation among teachers, as it is a means to improve teaching and learning processes and school and innovative professional practices. 
- It works to confirm good educational practices objectively and scientifically,since it is an introduction to professional and innovative development within the school, and it includes several steps, which are the procedure, observation, meditation and re-planning, then leaving the practices that prove useless in the teaching process.

- 5-An essential tool for all workers in the educational field, and a training medium characterized by flexibility and continuous renewal, which helps in developing and improving results.

Consequently, it has become vivid that action research is one of the most important tools for developing the educational and administrative fields, in the school community, for those who have a desire for professional and innovative self-development, as it isassociated only with active, participating and creative teachers in the educational process. Action research is an effective tool and one of the modern applied methodologies for bettering the professional practices of the teachers. It achieves several benefits such as students' learning and linking effectively between theory and practice.

\section{THE ROLE OF ACTION RESEARCH IN IMPROVING PROFESSIONAL PRACTICES AND INNOVATION AMONG FEMALE TEACHERS}

Among the professional practices of female teachers in the school community is cooperation, reflection, and profound, professional understanding, but this alone is not sufficient for a real change in professional practices of female teachers. Kraft (2002) affirms that the real change in teachers' professional practices and students' learning takes place when teachers investigate, through collaboration and critical thinking, into a phenomenon or a problem that attracts their attention. Joyce and Showers (2002) add that teachers' effective, professional learning appears through the use ofaction research based on the nature of practice and work. They must be prepared and supported to use this type of research because it provides real learning opportunities based on practice and reflection and then continuous improvement and development.

\section{PREVIOUS STUDIES/REVIEW OF THE LITERATURE}

Reviewingthe studies that dealt with action research shows that Arab studies in this field are scarce, if compared to foreign studies, and despite their scarcity, some studies related to the main variable of the research are presented here. One of these studies is Al-Shafi'I's(2013) study that aims at training teachers in conducting and measuring action research. This has affected the development of their self-efficacy, teaching practices, and attitudes toward the teaching profession. To achieve the purposes of the study, the researcher adopts the mixed research methodology by relying on quantitative and qualitative data through the application of five tools represented in: Self-Efficiency Scale, Scale of Attitude toward Teaching Science, Note for Student Teacher Performance, Standardized Interview Card for Teacher Student and Teacher Diaries. The results of the study indicated that the students' teachers have a low self-efficacy that negatively affected their attitudes towards science education and their teaching performance, which was overcome by conducting research work. The study also presented a proposed scenario for incorporating action research into teacher preparation programs.

In addition, Auxiliadora et al.'s (2011) studyaimed at explaining how to apply the methodology of action research at schools as an approach for encouraging and spreading a culture of professional development among teachers. The results of the study showed that training on carrying out action researches has contributed to developing teachers' ability to improve the school, to think critically, implement cooperative learning strategies, and participate in community activities that servethe school. 
Besides, the Chou-hui's study, (2011), aimed at highlighting the collective changes that appeared in the teaching practices of English language teachers and in their participation in professional learning societies. The study also sought to reveal the extent to which the contribution of the learning community and the effectiveness of action research tothe achievement of the professional development of the teachers. Data were collected through individual interviews with teachers, discussion groups, and the results of the study concluded that action research enables teachers to understand their practices, exchange knowledge, interact and learn from each other through their professional practices, and also contributes to improving student performance.

Moreover, the study of Ax, Jan, et al. (2008) attempted to describe the scientific experiences of students and the teachers of teachers with regard to action research and their incorporation into the actual practices of teachers. Students and science teachers were involved in three teacher preparation programs in the Netherlands, and action research was seen as a means of professional development. The study concluded that action research should be viewed from different angles as a professional approach and a set of skills required for making a link between theory and practice and as a way to improve practices through structured support for knowledge based on practices.

Furthermore, Inglides, Panayiotis, et al. (2005) conducted a study aiming at applying a collaborative model of action research for developing teachers professionally. The researchers developed and applied a collaborative model for action research, in which an academic professor from the university cooperated with a teacher at the school with the aim of Improving the teaching practices and the teaching capabilities of the teacher in multiple classes, and the results revealed the improvement of the practices of the teacher, since the teacher developed a large number of teaching techniques and mechanisms in the classroom.

\section{COMMENT ON PREVIOUS STUDIES}

Through presenting these previous studies, it has become clear that action research plays an important role in improving the school performance and the professional practices of teachers, as it has become an educational trend in many countries of the contemporary world. It is also clear that action research is an essential input for achieving the quality of the educational process. Generally, studies indicate the importance of approving action researches at schools because they have positive effects on teachers' self-efficacy, empowerment, and ability to solve professional problems. Some studies, such as those of Al-Shafii (2013) and Ax, Jan, et al (2008), dealt with the impact of action researches on preparing teachers before and during the service, and also emphasized their importance in the teacher preparation programs and the teacher's acquisition of knowledge and skills for conducting action researchesfor the sake of improving their professional practices and attitudes.

All studies, such as Chou-hui's (2011) and that of Angelides, Panayiotis, et al. (2005), unanimously agreed that the teachers' participation in conducting action research leads to improving their professional practices. The current research agrees with those studies, but there is no study applied to female teachers and students, as the current one. All studies also unanimously agreed that the participation of teachers in conducting action research leads to improving their professional practices.

\section{RESEARCH PROCEDURES}

This part of the research deals with a description of the field research procedures carried out by the researcher to achieve the research goal. It includes the research method, defining the research community, its sample, the research tool, verifying 
its validity and reliability and the statistical treatment used in analyzing the results.

\section{RESEARCH METHODOLOGY}

The research is based on the descriptive analytical method. This approach, which is based on collecting data and information in order to describe the phenomenon studied about action research, is the most appropriate way to achieve the goals of the study. A mixed method (which combines both quantitative and qualitative methods) was also used, as mentioned by Abu Allam (2013: 379), it is "a way for collecting, analyzing and mixing both quantitative and qualitative data in one study to understand the problem of research." It helps to highlight the strengths of both quantitative and qualitative data, since quantitative data, such as the degrees that we obtain from the tools that give us specific numeric data can be analyzed statistically by the SPSS program. It also gives us specific, qualitative information and data, which is done by questioning a sample from the research community through a survey interview and asking for the opinions of teachers about the concept of action research and its role in improving their professional practices and innovation.

\section{1-The Research Community and its Sample}

The research sample was chosen from female teachers in government secondary schools by means of a random cluster method according to the division of education offices, namely the North, South, East, West, Jumum, Bahra and Al Kamel. Each school had (45) female teachers, so the total number of individuals in the sample became (135) female teachers. Then, the questionnaire was distributed among members of the research community from the three female high school teachers. This distribution of female teachers was carried out according to the personal and organizational variables of the research as in table (1).

Table 1: Distribution of a Sample of Secondary School Teachers According to Personal and Organizational Variables $\mathbf{N}=\mathbf{1 3 5}$

\begin{tabular}{|c|c|c|c|c|}
\hline No & Variable & Classes & Repetition & Percentage \\
\hline \multirow{2}{*}{1} & \multirow{2}{*}{ Qualification } & Bachelor & 120 & 88,9 \\
\hline & & MA & 15 & 11,1 \\
\hline \multirow{2}{*}{2} & \multirow{2}{*}{ Specialization } & Science & 42 & 31,1 \\
\hline & & Literature & 93 & 68,9 \\
\hline \multirow{3}{*}{3} & \multirow{3}{*}{ Years of teaching experience } & Less than 5 years & 18 & 13,3 \\
\hline & & $5-10$ years & 42 & 31,1 \\
\hline & & $10-$ more & 50 & 37 \\
\hline \multirow{2}{*}{4} & \multirow{2}{*}{ Obtaining courses in action researches } & Yes & 10 & 7,4 \\
\hline & & No & 125 & 92,6 \\
\hline & \multicolumn{2}{|c|}{ Total sample population $(n)=135$} & & \\
\hline
\end{tabular}

\section{2- The Research Tool}

To achieve the goals of the research and to collect the data necessary for answering its questions, the research relied on a questionnaire to achieve its field goals of identifying the reality of the concept of action research among high school teachers and its role in professional and innovative development from their point of view.

The researcher designed two tools for the research questionnaire.

The first tool: to know the reality of the concept of action research among high school teachers from their point of view.

The second tool: The role of action research in improving professional practices and innovation for female 
teachers through access to theoretical literature and previous studies related to action research. It consists of (8) items.

Besides the personal data, represented by academic qualification, specialization, years of experience in teaching, obtaining courses in action research, the questionnaire contained four axes, namely: professional fellowship, professional cooperation, self-learning, professional and innovative development, in total (42) items. The first was a Professional Fellowship which consists of (12) items, then Professional Cooperation which consists of (12) items, then Self-learning, which consists of (8) items, and finally, Professional and Creative Development which consists of (10) items. The fiveLikert scale has been used:(very high, high, medium, weak, and very weak).

\section{3- Procedures for Codifying the Questionnaire}

In order to ascertain the truthfulness of the questionnaire by verifying the truthfulness of the arbitrators through presenting the questionnaire to a group of specialists and experts, from among the fellow faculty members of Umm Al-Qura University in Makkah, to express their opinion of it, and in light of theirremarks, the required amendments were agreed upon.

To ensure the consistency of the two research tools, they were applied to an exploratory sample, the stability was calculated, using the Alpha Kronbach transaction, and the results were as follows: The values of the parameters of the first tool were 0.94), and the values of the parameters of the second tool (0.95).These values assert the validity of the questionnaire for the application.

\section{RESEARCH RESULTS AND DISCUSSIONS}

Field procedures of the research sought to identify the reality of the concept of action research among high school teachers from their point of view, to know the role of action research in the professional development and creativityof the teachers, and to discover whether there were differences in the averages of the teacher responses about the concept of action research due to the different variables (qualification, Specialization, years of experience and courses on action research). The results were as follows:

The answer to the first main question was: 1 - "What is the concept of action research among high school teachers in Makkah from their viewpoint?" The mean averages and standard deviations for the dimensions of the first axis were calculated to determine the female teachers' concept of action research from their point of view, which was determined in four axes, and then arranged in a descending order according to the arithmetic averages for each axis. This can be shown in the following table (2):

Table 2: Arithmetic Averages and Standard Deviations in the Responses of Government Secondary School Teachers in Makkah about their Degree of Knowledge of the Concept of Action Research, Associated with its Descending Axes. $\mathbf{N}=135$

\begin{tabular}{|c|l|c|c|c|c|}
\hline No & \multicolumn{1}{|c|}{ Axes } & $\begin{array}{c}\text { Arithmetic } \\
\text { Mean }\end{array}$ & $\begin{array}{c}\text { Standard } \\
\text { Deviation }\end{array}$ & $\begin{array}{c}\text { Order of } \\
\text { Axes }\end{array}$ & $\begin{array}{c}\text { Degree of } \\
\text { Knowledge }\end{array}$ \\
\hline 1 & Professional cooperation & 0,98 & 0,25 & 1 & weak \\
\hline 2 & Professional fellowship & 0,97 & 0,32 & 2 & weak \\
\hline 3 & Self-education & 0,96 & 0,40 & 3 & weak \\
\hline 4 & Professional development and creativity & 0,95 & 0,45 & 4 & weak \\
\hline & $\begin{array}{l}\text { The total sum of the degree of knowledge of } \\
\text { action research }\end{array}$ & 0,97 & 0,36 & & weak \\
\hline
\end{tabular}


Table (2) shows that the degree of the female teachers' knowledge of action research is weak from the point of view of those government secondary school teachers in the Holy Makkah. The general mean of the total sum of their knowledge of action research was (0.97), with a standard deviation of (0.36) and the values of the standard deviations for the four axes of the first questionnaire ranged between (0.32-0.45) They are low values which indicate the homogeneity of the responses of secondary school female teachers in Makkah due to their lack of knowledge of action research.

It can be noticed from table (2) that the teachers' degree of knowledge of action research was weak as their ranking in the table comes from the viewpoint of members of the research sample from government secondary school female teachers in Makkah although some of them answered, as in table (1) that they attended some courses. This was a conclusion from the exploratory study concerning the question about their knowledge of the concept of action research, but the availability of the courses for some of the axes of the questionnaire, such as professional development, innovation and self-learning, confirms the efforts of the Ministry of Education to develop the teacher and his professional development through training.

To answer the second question: 2- What is the role of action research in improving the professional practices and creativity of secondary school teachers in Makkah from their point of view?

The arithmetic mean and the standard deviation for the responses of government secondary school teachers in Makkah were calculated around the second axis of the questionnaire whichmeasuresthe degree of female teachers' knowledge of the role that action research plays in professional development and creativity of female teachers in secondary schools, and then arranging those items in a descending order based on the arithmetic mean, as the results of Table (3) show:

Table 3: Arithmetic Averages and Standard Deviations for the Responses of Government Secondary School Teachers in Makkah About the Degree of Female Teachers' Understanding of the Concept of Action Research and The Role it Plays In Improving Professional Practices and Creativity for Female Teachers, in a Descending Order. $\mathbf{N}=\mathbf{1 3 5}$

\begin{tabular}{|c|l|c|c|c|c|}
\hline No & $\begin{array}{l}\text { Professional Practices Related to the Role that Action Research } \\
\text { Plays in the Professional Development and Innovation of Female } \\
\text { Teachers at the Secondary Level }\end{array}$ & $\begin{array}{c}\text { Arithmetic } \\
\text { Mean }\end{array}$ & $\begin{array}{c}\text { Standard } \\
\text { Deviation }\end{array}$ & $\begin{array}{c}\text { Order } \\
\text { of } \\
\text { Axes }\end{array}$ & $\begin{array}{c}\text { Degree of } \\
\text { Knowledge }\end{array}$ \\
\hline 1 & $\begin{array}{l}\text { The participation of female teachers in action research contributes to } \\
\text { enhancing cooperative work }\end{array}$ & 1,98 & 0,90 & 2 & average \\
\hline 2 & Female teachers tackle educational problems using action research & 1,99 & 0,65 & 1 & average \\
\hline 3 & $\begin{array}{l}\text { The teachers adopt new professional practices based on the results of } \\
\text { action research }\end{array}$ & 1,96 & 0,97 & 3 & average \\
\hline 4 & $\begin{array}{l}\text { The teachers change their professional practices as a result of using the } \\
\text { best alternative through action research }\end{array}$ & 1,29 & 0,25 & 7 & weak \\
\hline 5 & $\begin{array}{l}\text { Teachers change their negative perceptions of the role of action } \\
\text { research in continuous improvement when using it }\end{array}$ & 1,20 & 0,15 & 8 & weak \\
\hline 6 & $\begin{array}{l}\text { The teachers achieve the concept of self and continuous learning by } \\
\text { applying action research }\end{array}$ & 1,43 & 0,45 & 5 & weak \\
\hline 7 & Teachers address class performance problems with action research & 1,89 & 0,96 & 4 & weak \\
\hline 8 & The teachers belong to their innovative skills using action research & 1,40 & 0,20 & 6 & weak \\
\hline & The sum total of the degree of knowledge of action research & 1,39 & 0,60 & - & weak \\
\hline
\end{tabular}

Table (3) shows that the professional practices related to the role that action research plays in improving professional practices and innovation for female teachers in secondary schools came with a degree of their general knowledge (weak) from the point of view of government secondary school teachers in Makkah, where the general arithmetic average is $(1,39)$,with a standard deviation $(60,$.$) . The values of the standard deviations of most professional$ 
practices related to the role that research work plays in improving their professional practices and innovation for female teachers in secondary schools in the Holy Makkah in this tool ranged between $(15, .-45$,) which are low values, which indicates the homogeneity of the responses of the teachers about the extent of their knowledge of the concept of action research and its role in improving professional practices and innovation. As for the professional practices whose standard deviations are between (0.95-0.96), they are relatively high (medium) values, which indicates the variance of the teachers' responses about their knowledge of the role of action research in improving their professional practices and innovation in secondary schools.

Then, comes in the first arrangement of professional practices related to the role played by action research in improving the professional practices of female teachers in secondary schools and its contribution to solving educational problems, cooperative work, and the adoption of new professional practices and classroom performance problems as in the arrangement of Table (3). As for weak professional practices, perhaps it is due to their lack of knowledge of the concept of action research and the weak competencies and scientific skills related to the modern methodology for solving educational problems and classroom performance faced by female teachers in secondary schools, and that their attempts often depend on diligence, attempt and error. The lack of knowledge is a result of the lack of training and pre-service preparation and training programs for this type of research, despite its importance to solve these problems. The results also show the role of action research in improving the professional practices and creativityof female teachers in line with the nature of the concept of action research among high school teachers in the Holy Makkah, while the results of the research showed their limitations; lower than what was expected.These results from the point of view of the teachers came contrary to what was confirmed by theoretical literature which asserts thatthe research is a tool used to help teachers improve their professional practices and creativity. This meaning was confirmed by (Al-Shafi'i 2013), (Ax, Jan, et al. 2008), (Chou, 2011), and (Angelides, Panayiotis, et al. 2005) through their choice of modern teaching strategies, or solving educational problems related to female students, in addition to the fact that understanding the action research and its use leads to a positive change represented in the development of teachers and their self-learning, and enhancing their professional and innovative practices.

To answer the third question: 3 - Are there statistically significant differences between the averages of female teachers' responses to their knowledge of the role of action research which are attributed to the differences in qualification variables, specialization, teaching experience and access to training courses in the field of action research?

Table 4 :The Averages of Female Teachers' Responses to their Knowledge of the Role of Action Research, which are Due to the Differences in Qualifications, Specialization, Experience in Teaching, and Obtaining Training Courses in the Field of Action Research:

\begin{tabular}{|c|c|c|c|c|c|c|}
\hline No & Variable & Classes & Repetition & Mathematical Mean & $\mathbf{N}$ & Significance Level \\
\hline \multirow{2}{*}{1} & \multirow{2}{*}{ Qualification } & Bachelor & 120 & 88,9 & \multirow{2}{*}{0,63} & \multirow[t]{2}{*}{0,53} \\
\hline & & MA & 15 & 11,1 & & \\
\hline \multirow{2}{*}{2} & \multirow{2}{*}{ Specialization } & Science & 42 & 31,1 & \multirow{2}{*}{0,61} & \multirow[t]{2}{*}{0,40} \\
\hline & & Literature & 93 & 68,9 & & \\
\hline \multirow{3}{*}{3} & \multirow{3}{*}{ Years of experience in teaching } & Less than 5 years & 18 & 13,3 & \multirow{3}{*}{0,28} & \multirow{3}{*}{0,78} \\
\hline & & $5-10$ years & 42 & 31,1 & & \\
\hline & & 10 - more & 50 & 37 & & \\
\hline \multirow{2}{*}{4} & \multirow{2}{*}{ Obtaining courses in action researches } & yes & 10 & 7,4 & 0,43 & \multirow{2}{*}{0,31} \\
\hline & & No & 125 & 92,6 & 0,63 & \\
\hline & \multicolumn{3}{|c|}{ Total samplepopulation $(\mathrm{n})=135$} & & & \\
\hline
\end{tabular}


The results of the personal data, which are attributed to the different variables, as in Table (1), (2) and (4), as well as from the interviews that were conducted with them, indicate that the educational qualification, years of experience and specialization do not affect the different responses of the female teachers to the research sample about their knowledge of the concept of action research.Despite the fact that the greater the experience in teaching, the greater the culture of female teachers in the professional field, for their long practice and dealings with and solving educational problems, there are no statistically significant differences at the level of significance (0.05) among the responses of secondary school teachers; all of them are not influential. This is due to the fact that not all of the teachers have taken courses in actionresearch, either during pre-service preparation programs orthe training during the service;only training on some of the axes of the questionnaire. Although some members of the study sample were graduate students, the methods of scientific research presented in their graduate studies programs focused only on the usual research and neglect action research. This has been conceived by the researcher through her teaching in postgraduate programs, and her discussions with the students.

The degree of the female teachers' knowledge of the role of action research in professional practices and innovation was between medium and weak, inclining towards the latter. However, this did not rise to the hoped-for limit because practices related to action research have a role in improving professional and innovative practices for teachers and changing their negative perceptions about action research, continuous learning and addressing class problems.

\section{SUMMARY OF RESULTS}

The research reached many results that diagnose the existing situation regarding the concept of action research among high school teachers in Makkah, and its role in improving professional practices and innovation.

The results can be summarized as follows:

The degree of knowledge of secondary school teachers in Makkah with the concept of action research was medium, in the viewpoint of the high school teachers and was arranged as follows: (professional cooperation, professional fellowship, self-learning, professional development and creativity).

The degree of the secondary school teachers'knowledge of the role of action research in professional development and innovation came with a (weak) degree from the teachers' point of view.

There are no significant differences at the level of significance (0.5) about the degree of their knowledge of the concept of action research in terms of academic qualification, years of experience and specialization and access to training sessions, which does not affect the different responses of the parameters of the research sample.

\section{RECOMMENDATIONS AND SUGGESTIONS}

- Insertingaction research into pre-and in-service teacher preparation and training programs to be carried out through field training.

- Preparing faculty members who are specialized in how to conduct action research at general education schools

- Increasing awareness of the importance of using the methodology of actin research in dealing with educational problems, and improving female teachers' educational and vocational practices and creativity at schools

- Holding training courses and workshops for female teachers in the field of action research 
- Dissemination of the culture of action research among all female teachers in schools, educational supervision and society through holding seminars and distributing educational brochures which include the results of action research in order to encourage teachers and all workers to be creative and innovative in their professional practices and to provide solutions to educational problems at the school

- Collaborating with the colleges of education in designing training programs to train teachers on how to conduct action research

- Honoring distinguished female teachers who conduct research work at schools

- Conducting more scientific studies on action research and its role in improving the professional and innovative practices of teachers and school administration to determine the competencies necessary for its performance, and to know the reality of the regulatory environment that supports its performance at schools

- Training teachers before service on conducting action research within the curricula coursesatthe faculties of education

- Urging female teachers to attend conferences and seminars at the local, regional and international levels, and to participate in them with studies on action research

- Attending refreshing, catalyst courses in specialization and various educational subjects which are useful for the professional development of female teachers

\section{REFERENCES}

1. Abu Allam, Raja Mahmoud. (2013 AD). Quantitative, Qualitative and Mixed Research Approaches. Amman: Dar Al-Masirah.

2. Ahmed, Jamil Al-Sayed. (2011). "A suggested concept for the Requirements of using Situational Action research as an Introduction to the Professional Development of Industrial Secondary Education Teachers in Egypt".A PhD thesis. Assiut University, Faculty of Education.

3. Al-Ansari, Essa Hassan. (2004). "Teacher Training while in Service in the Kingdom of Saudi Arabia: Reality and Future". Journal of Psychological and Educational Research. vol. (19).Menoufia University: Faculty of Education:

4. Al-Antar, Yasser. (1434). The Leadership Role of SchoolPrincipals in Makkah in Developing Teachers Professionally: Perception and Practice from their Point of View. Master Thesis in the Holy Makkah: Umm Al-Qura University, College of Education, Department of Curricula, Educational Administration and Planning.

5. Al-Harbi, Abdullah Mazal. (2011). "A Proposed Scenario for Updating the Foundations of GeneralEducation Teacher Training Programs in the Kingdom of Saudi Arabia". Journal of the Faculty of Education. Vol. 35., Ain Shams University:

6. Al-Khaldi, Musa. (May, 2003). "How can Teachers Benefit from ActionResearch in Developing their Performance and Solving their Problems?" Educational Visions Magazine. No. 13. Ramallah: Al-Qattan Center for Educational Research.

7. Al-Khudaidi, Mamdouh. (1434). The Contribution of Educational Supervision in the Self-development of Secondary School Biology Teachers in the field of Teaching Skills. Unpublished Master Thesis. Makkah: College of Education, Umm Al-Qura University Department of Curricula and Teaching Methods.

8. Peterson, D., (2002). Positive or negative? Journal of staff development,23(3), PP 10-15 
9. Al-Rumaih, Abdul Rahman. (1425). The Resident Educational Supervisor's Role in Professional Development for Teachers. Unpublished Master Thesis. Riyadh: King Saud University College of Education, Department of Educational Administration.

10. Al-Shafi'i, Jihan. (2013). "Training Student Teachers in the Biology Division of the Faculty of Education, Helwan University in Conducting Action Research as a Basis for Improving Self-efficacy, their teaching practices and their attitudes toward the Teaching Profession: Case Study". Educational Journal, No. 106. Part II. Egypt: Helwan University, Faculty of Education: 183-235.

11. Al-Shahrani, Ali. (2011). A proposed Concept for Establishing a National Center for Professional Development for Teachers in the Kingdom of Saudi Arabia in the Light of the Philosophy of Continuing Education. Journal of the Association of Modern Education: 271-340.

12. Al-Tamimi,Abdulaziz. (1430). The role of School Principals in the Professional Development of Teachers: A field Study on Ras Tanura.Unpublished Master Thesis.Riyadh: Imam Bin Saud Islamic University, College of Social Sciences, Department of Education.

13. Al-Zaidi, Ahmed Mohamed. (2013). "The Professional Requirements of Education Societies as an Introduction to School Reform: A Proposed Vision". Journal of Education. Egypt: Al-Azhar University, Faculty of Education.

14. McKinnev, Jinn. (2001) Action Research. Trans. by Ismail Al-Qaqawi. Ramallah: Al-Qattan Center for Educational Research and Development.

15. Odeh, Rahma Muhammad, and Randa Eid Sharir. (2004, 23-24 November). "Action Researches as an Introduction to Improving the Educational Process in Light of Recent Changes". Research presented to the first conference "Education in Palestine and the Changes of the Age". Gaza: the Islamic University.

16. Rawas, Faiza Ahmed. (2001). Evaluating the Training Centers Programs at the General Presidency for Girls' Education in Makkah from the Viewpoint of Training and Trained Managers.Unpublished Master Thesis.The Holy Makkah: Umm Al-Qura University, Faculty of Education, Department of Curricula.

17. Sa'adawi, Haniya Abdullah. (2016). The Availability of Strategic Teaching Skills in the Teaching Practices of Female Chemistry Teachers at the College of Education, University ofUmm Al-Qura. Vol. 18. Cairo: The National Center for Examinations and Educational Evaluation.

18. Thekra, Lawrence Basta. (2003, May 18-20). "Teacher Professional Development Models with Focus on Performance Research Model - Analytical Study. The Fourth Scientific Conference: "Professional Development for Personnel in PreUniversity Education - A Future Vision. Cairo: National Center for Educational Research and Development.

19. Zahrani, Ali. (1425). The Role of Educational Supervision in Developing Teaching Skills.Unpublished Master Thesis, Department of Curricula, College of Education, Umm Al-Qura University, the Holy Makkah.

20. Kraft, P., (2002). Teacher researches a way to engage in critical reflection: A case study. Reflective Practice 3, No. $2<P P$ 175-89.

21. Mertler, A., (2006). Action research: Teachers' as researchers in classroom. Thousand Oaks, CA: Sage.

22. Mills, G.,(2003). Action Research A Guide for Teacher Researcher, New Jersey, Merrill Prentice Hall.

23. Niff, J.,(2014). Action Research for Professional Development, Concise Advice for New Action Research Available at, www. Action research, net,2002, Retrieved 2014.

24. Norton, L., (2009). Action Research in Teaching \& Learning, London, Routledge.

25. Peterson, D., (2002). Positive or negative? Journal of staff development,23(3), PP 10-15 
26. Sergiovanni, T., (2006). The Principalship: A reflective Practice Perspective, New York, Pearson Education.Stringer, T.,(2007). Action research, 3ed.San Francisco, CA: stage.

27. Angelides, Panayiotisal, (2005, Julie). Implementing a Collaborative Model of Action Research for Teacher Development, Educational Action Research, Vol. 13, No. 2.

28. Auxiliadora, et al, (2011, Juli). Action Research as aschool Based Strategy in Intercultural Professional Development for Teachers. Teaching and Teacher Education. 27, No. 5.

29. Ax, Janet al,(2008, Nov.). Action Research in initial teacher education: An Explorative Study, Educational Action Research, Vol. 16, No. 1.

30. Chiou- hui, C., (2011). Teachers' Professional Development:Investigating Teachers' Learning to Do Action Research a Professional Learning Community.The Asia-Pacific Researcher.20:3, PP421-437

31. Darling, L. (2006). Powerful teacher education: Lessons from exemplary programs. San Francisco, CA: Jossey-Bass.

32. Deal, T. and Peterson, D. (2009). The shaping school culture field book. Francisco, CA: Published by Jossey-Bass.

33. Garcia, M., and Robin, P. (2008). Innovation, research and professional development in higher education: Learning from our experience.Teaching and Teacher Education.24(1),104-106.

34. Good, Carter, (2008). Dictionary of Education, McGrow Hill, Open University Press.

35. Hewitt, R.\& Little, M. (2005). Leading Action Research in Schools, Bureau of Exceptional Education and Student Services, Florida Department of Education.

36. Joyce, B., and Showers, J. (2002). Student achievement through staff development. Alexandria, VA: Association for Supervision and Curriculum Development.

37. Kemmis, S.\& Mc Taggart, R.,(2008). The Action Research Planner, Australia, Deakin University Press.

38. King, B., and Newman, M.(2000). Will teacher be learning advance school goals? Phi Delta Kappan,81, PP576-580. 